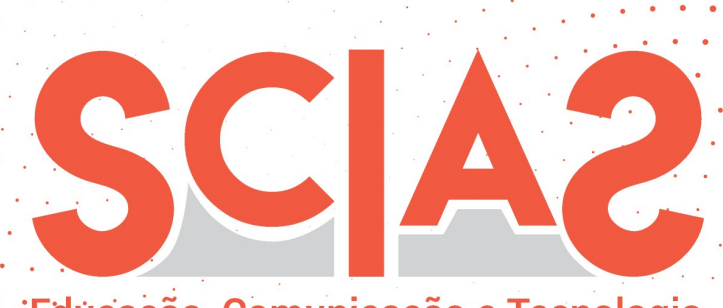

'Edúçaçã̃o, Comunicação e Tecnologia'

Atribuição BB CY 4.0

\title{
Mãe-pesquisadora: Os impactos do isolamento social em minha produção acadêmica durante a pandemia de COVID-19
}

Eliziane Cristina da Silva de Oliveira ${ }^{1}$

\section{Resumo}

A pandemia de Covid-19 provocou mudanças significativas nas relações humanas e sociais em todo o mundo. $\mathrm{O}$ isolamento social, medida protetiva inquestionável para conter a propagação do vírus e controlar os números de casos de doentes, afirmou mudanças impactantes ao trazer para o ambiente doméstico todas as atividades escolares e profissionais, o que causou também mudanças, por exemplo, no ritmo da produção acadêmica, especialmente, de mulheres mães pesquisadoras. Nesse depoimento, conto um pouco de minha rotina doméstica, profundamente alterada nesse momento atípico que estamos vivendo, com acréscimo de atividades, observância de novos horários e novas exigências, e também como essas alterações interferem em minha produção intelectual e no cumprimento de prazos regulamentares e outras exigências típicas de programas de pós-graduação. Conto também um pouco dos desafios enfrentados em minha casa e as soluções que estou encontrando para não deixar que o desconcerto dos dias pare minha pesquisa e projetos acadêmicos.

\section{Palavras-chave}

Produção intelectual. Mães pesquisadoras. Covid-19. Isolamento social

Recebido em: 14/07/2020

Aprovado em: 26/01/2021

${ }_{1}^{1}$ Doutoranda e Mestre em Estudos de Linguagens pelo Centro Federal de Educação Tecnológica de Minas Gerais (CEFET-MG), com pesquisas nas áreas de fotojornalismo, edição fotográfica e narrativas visuais. Professora, jornalista e fotógrafa.

E-mail: elizianes@hotmail.com 


\section{Mother-researcher: The impacts of isolation Social in my academic production during the COVID-19 pandemic}

\section{Abstract}

The Covid-19 pandemic caused significant changes in human and social relations around the world. Social isolation, an unquestionable protective measure to contain the spread of the virus and control the numbers of cases of patients, affirmed impactful changes by bringing all school and professional activities to the home environment, which also caused changes, for example, in the pace of education. Academic production, especially by female research mothers. In this testimony, I tell you a little about my domestic routine, profoundly altered in this atypical moment that we are living, with increased activities, observance of new schedules and new requirements, and also how these changes interfere in my intellectual production and in meeting regulatory and regulatory deadlines. Other requirements typical of graduate programs. I also tell you a little about the challenges faced in my home and the solutions I am finding to not let the disconcert of days stop my research and academic projects.

\section{Keywords}

Intellectual production. Research mothers. Covid-19. Social isolation 
Começo a escrever este texto às 23 ho3 do dia 9 de julho de 2020. Esses momentos, a essa hora da noite, são dos raros em que o silêncio, em uma casa movimentada e com a rotina totalmente alterada, se faz presente. Esse é o $112^{\circ}$ dia de isolamento social a que fomos obrigados devido à pandemia de Covid-19 desde o dia 16 de março. Nesse período, muitas coisas mudaram em nossas vidas - na minha e na de centenas de milhões de pessoas no mundo inteiro. Inclusive de pesquisadoras, como eu, que passaram a dividir o tempo antes dedicado à pesquisa com todas as outras atividades domésticas e escolares das crianças, essas antes divididas entre a escola e as famílias e que, sem que houvesse tempo para um preparo, foram assumidas, pelo menos em maior parte, pelas famílias.

Sou pesquisadora da área de linguagens e tecnologias, cursando o último ano do doutorado em Estudos de Linguagens no Centro Federal de Educação Tecnológica de Minas Gerais (CEFET-MG). E, antes do título acadêmico, sou mãe de duas meninas, de oito e quatro anos, que assim como eu, estão com a vida escolar virada de ponta-cabeça, com as salas de aula trazidas para a sala de casa e todas as limitações impostas pela necessidade inquestionável de permanecermos recolhidos em nossa habitação, sem contato com familiares, amigos, professores e todas as pessoas que compõem nossas redes de relacionamentos profissionais e afetivos. Sim, afetivos, porque aprendizados e formação são também processos marcados pelas emoções, assim como nossas relações com aqueles que amamos.

Voltando à minha vida acadêmica, nove dias antes do início do isolamento social, no dia 27 de fevereiro de 2020, eu havia protocolado na coordenação do programa de pós-graduação ao qual estou vinculada, com a anuência do meu orientador - o Professor Doutor Wagner Moreira -, um pedido de prorrogação de defesa de tese, prevista, de acordo com os prazos regulamentares, para até 28 de fevereiro desse ano. Um atraso em uma das etapas de minha pesquisa me demandou um tempo maior de análise e escrita e, ao solicitar 90 dias de prazo adicional para a defesa, a nossa ideia, minha e do meu orientador, era que mais um mês seria suficiente para finalizar a tese, outro mês para revisões e organização da banca e, finalmente, um mês de prazo para leituras por parte dos 
integrantes da banca e preparação de minhas apresentações para a defesa pública. Isso porque, em "condições normais de temperatura e pressão", minhas tardes, até o início da pandemia, eram dedicadas à produção científica, pois nesse horário do dia as crianças estavam na escola, o que me permitia ler, escrever e analisar meus objetos de pesquisa de forma contínua, sem as interrupções comuns das necessidades sempre urgentes das crianças, que chamam "mamãe" a cada 30 segundos.

As tardes eram, até então, o período do dia em que eu produzia não somente minha pesquisa, mas artigos e apresentações e todas as demais demandas, inclusive as burocráticas, pertinentes à pós-graduação. Mesmo com as tardes utilizadas para essa finalidade, não era incomum usar as noites para leituras e escritas, o que me dava a sensação real de produtividade, aliás, essa palavra ligada a ações que nos são cobradas diariamente e que, muitas vezes, acaba por nos colocar sempre em uma posição de ouvir cobranças diversas e cada vez maiores sobre a nossa realização acadêmica, como se a experiência e a construção de saberes e de conhecimentos fosse uma padaria com fornos com tecnologia de ponta que produzem artigos e dossiês na mesma velocidade em que os pães são feitos, assados e ofertados aos consumidores sempre ávidos por pães novos e frescos.Nesse aspecto da avidez e cobranças feitas pelos órgãos responsáveis pelos programas de pós-graduação e também pelas agências de fomento à pesquisa, não há privilégios quando pensamos em gêneros. Tanto pesquisadores, quanto nós, pesquisadoras, somos cobrados na mesma proporção, a despeito das questões estruturais que diferenciam de forma cruel homens e mulheres em nossa sociedade. Entretanto, essas questões não são levadas em consideração quando pensamos a diferença da produção acadêmica de homens e mulheres, não no que diz respeito à qualidade, mas no volume de trabalhos publicados e/ou apresentados por homens e mulheres em diversos encontros, congressos, simpósios e todos os correlatos, bem como nas publicações científicas em periódicos nacionais e internacionais, especialmente naqueles que são melhor ranqueados nos critérios Qualis da Coordenação de Aperfeiçoamento de Pessoal de Nível Superior (CAPES). E isso fica mais evidente em momentos como o que estamos vivendo, em que todos nós voltamos para nossas casas como forma de auto-proteção e proteção social. 
Todavia, as casas precisam funcionar e, para isso, uma lista interminável de tarefas precisa ser realizada diariamente para que isso ocorra. Em situações ideais, essas tarefas deveriam ser divididas igualmente entre os moradores de forma que todos participem dos cuidados com o espaço comum, sem que haja sobrecarga de um ou outro membro da família.Mas, em nosso mundo marcado historicamente por desigualdades também nesse aspecto, nem sempre funciona assim. Voltando às diferenças estruturais e até mesmo ao machismo de nossa sociedade, a grande maioria dessas tarefas domésticas intermináveis recai sobre as mulheres. E quando há crianças na casa, a lista de afazeres cresce, contribuindo não somente para o cansaço físico, mas também mental e emocional. $\mathrm{O}$ que, no caso de mulheres mães pesquisadoras tem contribuição decisiva para a queda brusca da produção intelectual. Num momento atípico e imponderável como esse que todo o mundo vive desde o início deste ano, às tarefas domésticas se somam todas as demandas educacionais relacionadas às crianças e adolescentes, que vão desde as aulas online às tarefas de casa, lembrando, claro, que todas essas atividades são realizadas, agora, no ambiente doméstico. E assim como os cuidados com a casa, as responsabilidades decorrentes dessa nova forma de ensino também recaem, na maioria das vezes, sobre as mulheres.

Aqui em minha casa são duas crianças em idade escolar, ou seja, as atenções, da minha parte nesse aspecto, são divididas durante toda a tarde, sim... todas as tardes, de segunda a sexta-feira, entre as duas meninas, com acesso às plataformas adotadas pela escola em que elas estudam, as conversas e reuniões com professores e coordenadores, a resolução de problemas e imprevistos tecnológicos e até orientações sobre as formas de se usar uma nova ferramenta de aprendizado e, porque não dizer, de interação social, essa questão tão primordial na formação humana de cada um de nós. Então, as necessidades são, sem nenhum exagero de minha parte, aumentadas na medida em que se passam os dias e não enxergamos um horizonte de um retorno, mínimo que seja, a certa normalidade em nossas vidas, que estão mudadas, pelo menos até hoje, pelo número de mais de 65 mil óbitos pela Covid-19, o que provoca em adultos e crianças um deslocamento e um questionamento em relação à percepção da vida e de sua importância, de seu valor, neste país e em nossas casas. E, nesta 
situação, temos não somente as necessidades físicas ou materiais. São também as demandas emocionais, como o choro causado pela saudade dos amigos, da escola, dos professores, dos familiares e até da prática da natação. E, acalmar essas situações gera, para além do cansaço físico, um esgotamento emocional capaz de interferir em outros aspectos da vida cotidiana, especialmente na escrita acadêmica e todos os seus desdobramentos.

O que dizer, então, da minha rotina como pesquisadora dentro desse contexto remexido que viraram nossas vidas? Confesso que, mesmo antes da necessidade de permanecermos em casa como uma das poucas certezas que temos até hoje de se minimizar o risco de contaminação por um vírus tão agressivo, a execução das tarefas domésticas e maternas já tomavam parte considerável do meu tempo. Havia, e há, uma exigência de uma disciplina muito rigorosa para que todos os compromissos e prazos acadêmicos fossem e sejam cumpridos inclusive para que não haja punições ao programa de pós-graduação que, mesmo nesse contexto de anormalidade, continuam sendo cobrados por prazos e produção acadêmica. E, não sem motivo, essas cobranças são estendidas a todos os alunos e pesquisadores. No meu caso, embora a instituição tenha optado por tratar as questões com mais tranquilidade e até suspensão temporária do calendário acadêmico, não deixa de haver cobranças para cumprimento de prazos numa cadeia vertical de exigências até para a classificação dos programas, como todos nós sabemos que isso ocorre. Se em situações normais essas cobranças geram uma sobrecarga mental e até adoecimento de muitos pós-graduandos, nesse momento, imagino não ser diferente e até mais grave.

Nesses quase quatro meses, passei por situações diversas no desenvolvimento de meus trabalhos acadêmicos. Tendo já cumprido todos os créditos e executado todas as tarefas e compromissos obrigatórios, como estágios, publicações e participações em eventos científicos, a maior parte de minhas tarefas eram, sim, realizadas em casa, com todos os meus materiais de trabalho e objetos de pesquisa organizados no escritório de forma que, a qualquer horário que eu entrasse lá - e as meninas só entravam com minha autorização expressa para que não tirassem meus materiais da ordem que eu considerava necessária e 
adequada para meu ritmo de trabalho - eu conseguia produzir, retomando as linhas de raciocínio de onde havia parado. Com o isolamento social e as crianças com aulas remotas, toda essa estrutura teve que ser reorganizada. Ou melhor, desmontada. O notebook que eu uso para a pesquisa passou a ser compartilhado com minha filha mais velha para que ela participe das aulas. Além das crianças em casa, meu marido também trabalha quase 100\% do tempo, em home office, nesse mesmo ambiente, ou seja, uma casa que agora abriga dois escritórios profissionais e duas salas de aula. Nos primeiros meses do isolamento, havia ainda outro fator importante e não menos cansativo: gerenciar as novas formas de convivência e uso dos espaços da casa. E, mais uma vez, trabalho a mais para a mãe pesquisadora gerenciadora das crises domésticas: não podemos falar alto, temos que respeitar o trabalho do outro, entre outros episódios. Mas numa casa com crianças, onde a vida pulsa com toda sua intensidade, nem sempre é possível evitar gritos, brigas e outros conflitos, mas também há toda a carga de alegria, risadas, gargalhas e conversas sempre regadas a muitas expressões e "tiradas" que nunca mais sairão de nossas memórias. Com o passar dos dias, essas questões foram se acomodando com a participação e entendimento de cada um de nós e, agora, são menos conflitos para administrar no que diz respeito à utilização comum do espaço nas 24 horas dos dias.

Reconhecendo todas essas variações e reorganizações necessárias, minha pesquisa, em uma de suas fases mais cruciais que é a finalização da produção da tese, sofreu uma grande desaceleração. Posso dizer que foi mais que isso, foi uma freada brusca provocada por um esgotamento físico enorme e um desgaste emocional não somente pela situação imposta pela pandemia. Mas também pela incapacidade de realizar tarefas necessárias da pesquisa, sob a pena de não cumprir os prazos regulamentares. Nos primeiros 60 dias, fiz pouco ou quase nada da tese porque realmente não havia condições práticas para isso: além de todas essas mudanças, optamos por deixar a diarista em casa. Então, todas as atividades antes realizadas por ela em casa, inclusive no auxílio com os cuidados com as meninas, passaram a ser executadas por mim. E há outro aspecto que faz muita diferença: ela está conosco há mais de dez anos, muito antes do nascimento das crianças, que, hoje, sentem falta da presença cheia de afeto dela entre nós e perguntam, quase que diariamente, que dia a Tia Lúcia volta. E aí 
veio o sentimento de incapacidade ou de não estar no lugar certo na vida profissional e acadêmica. Outro fator contribuiu muito para que eu me sentisse assim: via e ouvia, por meio das redes sociais digitais, um mundo de atividades acadêmicas, lives sobre diversos temas relacionados às pesquisas que realizo, entre outras. Eu, no meu universo materno e doméstico recheado de tarefas e atribuições cada vez mais exigentes, não consegui participar de nenhuma delas. E me senti muito mal e, em certa medida, até não merecedora de estar no lugar que estou. Depois, passei a pensar que todas as pessoas que participam têm suas particularidades e sem fazer julgamentos - delas e também sobre mim - tenho me esforçado para compreender que não tenho que me obrigar a participar dessa grande movimentação acadêmica virtual que está ocorrendo.

Imagino que muitas dessas atividades continuarão a ser realizadas nos novos formatos que surgiram e ainda estão surgindo. Coloquei como meta terminar minha tese e vou, na medida do possível, fazer isso com dedicação e qualidade. E para isso, além do que depende de mim, a despeito de todas as variáveis externas que têm impacto direto em minha vida acadêmica, conto com um apoio enorme, constante e quase terapêutico de meu orientador. Nessas horas, com todas as dificuldades registradas até aqui, faz toda a diferença contar com uma presença - ainda que seja uma não-presença física em função do isolamento social - que soma e agrega ao processo de construção de uma pesquisa. E sendo assim, passados quase quatro meses de tantas mudanças, a mãe pesquisadora tenta renascer para finalizar o doutorado, não sem mais um baque antes. Nos primeiros dias de julho, um comunicado do programa de pósgraduação, dirigido aos alunos que ingressaram em 2016, o meu caso, teriam até 31 de agosto para realizar as defesas de forma a não prejudicar a avaliação trianual que será feita pela Capes. Ao ler a mensagem, imaginei que outros colegas pesquisadores, com ou sem filhos, que estão passando pelas mesmas angústias também tiveram sentimentos semelhantes. Um desespero tomou conta dos meus pensamentos e, junto dele, uma tristeza e o medo de não conseguir finalizar tudo. Passado esse momento, de alguma forma, a serenidade voltou e compreeendi que posso dar conta, não no prazo estipulado, tão exíguo e logo ali no horizonte dos dias. Mas será possível, ainda que para isso, as horas de escrita sejam as das noites e madrugadas, quando a casa silenciar com o sono 
das crianças. Enquanto escrevo esse testemunho, me chega uma matéria publicada no site do jornal espanhol EL PAÍS sobre uma pesquisa feita na Europa sobre mulheres profissionais com atividades em home office que conseguem trabalhar apenas durante a madrugada, quando há condições para concentração e realização de atividades que têm um exigência maior de raciocínio e reflexão. Seja na Europa ou aqui, no Brasil, essa realidade pode ser comprovada por mim ou qualquer uma das minhas amigas pesquisadoras acadêmicas ou profissionais de outras áreas de atuação que estamos passando por essa situação que não escolhemos passar. Ler tantos depoimentos, com relatos tão marcantes e profundos, reforça-me o sentimento de que, feliz ou infelizmente, não estou sozinha nesse mar de incertezas e sobrecargas e,mesmo que as condições não sejam as ideais, nossas vidas seguem com todas as assimetrias nas divisões de tarefas domésticas, dos cuidados com as crianças, tão expostas e ampliadas nesse momento, todas nós vamos adaptando-nos às novas rotinas e condições para dar conta daquilo que nos propusemos a realizar. Depois do comunicado enviado pelo programa sobre a necessidade de se cumprir prazos estabelecidos, uma nova questão burocrática surgiu e foi necessário fazer uma nova solicitação de prorrogação de defesa, mais noventa dias, que começaram a ser contados a partir do dia $1^{0}$ de julho. Ou seja, oficialmente, tenho até 30 de setembro para dar conta de revisar dois capítulos prontos e agregar a eles as sugestões e orientações recebidas na banca de qualificação, terminar um terceiro que está em curso e escrever o último deles e a conclusão. Para quem está de fora, pode parecer pouco, ou quase nada. Em situações normais, poderia ser menos trabalhoso ou cansativo, mas quando há necessidade de se dividir e recortar o tempo dos dias, que têm só 24 horas, para dar conta das tarefas acadêmicas e tantas outras tarefas domésticas e maternas, realmente fica difícil relativizar e dizer que será fácil. Os assuntos da pesquisa não me saem do pensamento e, apesar de tantas outras atribuições exigentes do momento, as reflexões e análises entram em linhas de raciocínio e tensão, pontos cruciais para que a pesquisa prossiga. E é a isso que me apego para continuar e finalizar esse projeto ao qual me dedico com carinho. Sim, carinho porque se não houver afeto numa pesquisa de, no mínimo, quatro anos, os sofrimentos se multiplicam exponencialmente e as chances de sucesso serão consideravelmente reduzidas. E no meu caso, ainda coloco no sistema de pesos 
e contrapesos, realizar uma pesquisa com duas crianças pequenas em casa, ressaltando o fato de que são duas meninas, os valores que desejo que elas apreendam para a vida e não somente para esse momento que estamos passando.

Desejo para elas e todas as outras meninas do mundo condições melhores e mais justas de vida, seja no direito de fazer escolhas profissionais e acadêmicas, seja na vida pessoal, com mais justiça e igualdade na divisão de tarefas, na remuneração. Então, superar adversidades e lutar para diminuir essas desigualdades não é somente um exercício para se cumprir metas acadêmicas ou terminar um doutorado a despeito das condições e situações que vivemos no mundo pandêmico neste ano de 2020. É uma utopia - e sim, elas nos movem plantar sementes para que meninas das gerações que se seguem e seguirão à minha não tenham a necessidade de passar pelo que passamos e ver suas produções acadêmicas - em um futuro, talvez - diminuídas ou extintas em função de sobrecarga com atividades domésticas e maternas,uma vez que hoje são realizadas em todos os lugares do mundo prioritária ou quase exclusivamente por mulheres. Nós, mulheres pesquisadoras que somos também mães somos cobradas nas mesmas medidas que os nossos pares masculinos e somos questionadas porque nossas produções científicas se dão em menor número. Um olhar um pouco mais atencioso nos dá as pistas necessárias para entender essas questões. E eu vou contar um exemplo pessoal: finalizo esse depoimento em uma manhã linda de domingo, às 9h42. Ao meu lado, num novo escritório improvisado em casa, esta, adaptada e reorganizada para abrigar as necessidades de todos nós enquanto durar o isolamento social, está uma criança de quatro anos, conversando com toda a sua alegria, chamando-me quase o tempo todo para mostrar os desenhos que está fazendo com meus materiais lapiseiras, canetas e tudo o mais que encontra no estojo. Para esse texto que escrevo agora, cujas questões estão tão introjetadas em mim e fluem para o papel com mais facilidade porque é um momento de catarse, a presença dela e as interrupções que me faz não interferem na escrita.

Mas esse não é o caso de outras escritas mais exigentes, como a minha tese em curso.Para essas, é necessário um tempo e um silêncio que fazem assentar as 
leituras teóricas, as reflexões e o lugar em que são encontradas respostas para o que se propôs a pesquisa e a pesquisadora. É necessário outro tempo de visitas e revisitas aos objetos de pesquisa e estudo, as fontes mais profundas de outras tantas respostas precisas e que vão, todas ou quase todas para o texto. Em minha pesquisa, os objetos são visuais - estudo as narrativas fotográficas de Sebastião Salgado sobre o continente africano - e precisam ser lidos de formas diferentes como lemos esse texto ou qualquer outro cujos sinais e elementos textuais ou verbais se façam presentes. A leitura de imagens requer outro tempo para que as subjetividades afloradas nas fotografias estudadas e em suas várias possibilidades de leitura nos apontem as intencionalidades presentes coletivamente na construção das narrativas. E todo esse tempo, precioso e crucial, encontra-se, em minha vida, nesse momento, fragmentado. Não se trata de aproveitar cada minuto, como alguém poderia sugerir. Ou de acordar mais cedo, antes de as crianças acordarem e movimentarem a casa. Minutos isolados não solucionam minha necessidade $e$, de verdade, não sei quando terei um bloco de tempo maior para que as análises sejam feitas da forma que idealizei. Estar em casa, o tempo todo, com todos nós em casa significa ter tarefas e afazeres durante todas as horas do dia. Então, acordar cedo ou tarde, é somente transferir o horário de uma ou outra tarefa, porque entre tantas, há algumas cujos horários são intransferíveis. E para escrever, produzir conhecimento de forma responsável e minimamente coerente, não é adequado ter todo o tempo ocupado de forma sobrecarregada.

É preciso um tempo para que as conexões sejam feitas. É necessário desligar, por um tempo que seja, a chave de outras atribuições. Como não disponho desse tempo ideal hoje, e nem sei se num horizonte de curto prazo o terei, continuarei a escrever durante as noites e madrugadas para cumprir os prazos necessários e exigidos para a finalização de minha tese e para a defesa. Penso que tudo isso que estamos vivendo poderá ter um impacto negativo na qualidade do que estou produzindo, mas entendo também que outras pessoas, inclusive outras mães pesquisadoras, também estão passando por situações semelhantes à minha e, cada uma com seu esforço, também está seguindo suas trilhas e batalhas. E é por mim e também por cada uma delas que me acompanha nessa caminhada que seguirei e apresentarei um trabalho com a melhor qualidade que eu puder. 
Não é apenas uma questão de honra, mas de capacidade, de solidariedade e, porque não, sororidade - para usar uma palavra que anda comum entre nós nesses tempos - para que saiamos fortalecidas desse momento e possamos continuar nossas batalhas juntas, para que o mundo, inclusive o da academia, seja mais justo, honesto e correto ao reconhecer que as diferenças entre gêneros não podem ser utilizadas para justificar outras diferenças que tornam a balança da vida tortuosa e ilegítima.

\section{Referências}

GARCIA, Janaína. Produção científica de mulheres despenca na pandemia - de homens, bem menos. Tilt/UOL, 26 de maio de 2020. Disponível em: https://www.uol.com.br/tilt/noticias/redacao/2020/05/26/pandemia-pode-acentuardisparidade-entre-homens-e-mulheres-na-ciencia.htm

RAMÍREZ, Noelia. "Trabalho de madrugada porque não dou conta de tudo em casa", a nova normalidade massacra as mulheres. Jornal El País, Coluna SMODA, 28 de maio de 2020. Disponível em: https://brasil.elpais.com/smoda/2020-05-28/trabalho-de-madrugada-porque-naodou-conta-de-tudo-em-casa-a-nova-normalidade-massacra-asmulheres.html?ssm=whatsapp 